\title{
Toward Fluorinated Spacers for MAPI-Derived Hybrid Perovskites: Synthesis, Characterization, and Phase Transitions of $\left(\mathrm{FC}_{2} \mathrm{H}_{4} \mathrm{NH}_{3}\right)_{2} \mathrm{PbCl}_{4}$
}

\author{
Claudia Lermer, ${ }^{\dagger, \ddagger}, \S$ Susanne T. Birkhold, Igor L. Moudrakovski, ${ }^{\dagger}$ Peter Mayer, ${ }^{\ddagger}$ Leslie M. Schoop, ${ }^{\dagger}$ \\ Lukas Schmidt-Mende," and Bettina V. Lotsch ${ }^{*},+, \$, \S$
}

\author{
${ }^{\dagger}$ Max Planck Institute for Solid State Research, Heisenbergstraße 1, 70569 Stuttgart, Germany \\ ${ }^{*}$ Department of Chemistry, University of Munich (LMU), Butenandtstraße 5 13, 81377 München, Germany \\ ${ }^{\S}$ Nanosystems Initiative Munich (NIM) \& Center for Nanoscience, Schellingstraße 4, 80799 München, Germany \\ "Department of Physics, University of Konstanz, Universitätsstraße 10, 78457 Konstanz, Germany
}

\begin{abstract}
The intrinsic moisture sensitivity of the hybrid perovskite methylammonium lead iodide (MAPI) calls for new synthetic strategies to enhance moisture resistance and, thus, long term stability. Here, we combine two strategies: (i) transitioning from $3 \mathrm{D}$ to $2 \mathrm{D}$ hybrid perovskites by inserting larger A site cations as spacers and (ii) using fluorinated linkers to enhance the hydrophobicity of the material-and identify two new hybrid perovskite type compounds, $\left(\mathrm{FC}_{2} \mathrm{H}_{4} \mathrm{NH}_{3}\right)_{2} \mathrm{PbCl}_{4}$ and $\left(\mathrm{FC}_{2} \mathrm{H}_{4} \mathrm{NH}_{3}\right) \mathrm{PbBr}_{3} \cdot \mathrm{DMF}$, carrying 2 fluoroethylammonium $\left(\mathrm{FC}_{2} \mathrm{H}_{4} \mathrm{NH}_{3}\right)^{+}$as a promising organic cation for the synthesis of moisture resistant hybrid perovskites. $\left(\mathrm{FC}_{2} \mathrm{H}_{4} \mathrm{NH}_{3}\right)_{2} \mathrm{PbCl}_{4}$ features a two dimensional structure and pronounced long term stability as confirmed by single crystal and powder $\mathrm{X}$ ray diffraction. The observed reversible phase transitions at 87 and $107^{\circ} \mathrm{C}$ investigated with thermal analysis, temperature dependent powder $\mathrm{X}$ ray diffraction measurements, and ${ }^{1} \mathrm{H},{ }^{13} \mathrm{C}$, and ${ }^{207} \mathrm{~Pb}$ solid state NMR spectroscopy can be assigned to changes in the inorganic lead

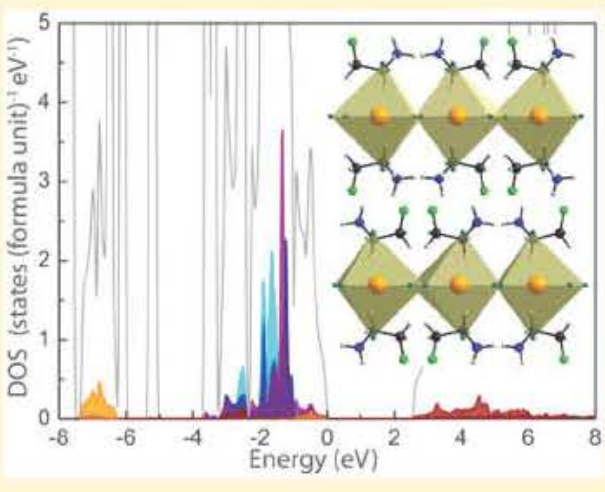
chloride and organic sublattices, respectively, both having clearly observable fingerprints in the solid state NMR spectra. DFT calculations trace the origin of the observed severe distortion of the inorganic sublattice in $\left(\mathrm{FC}_{2} \mathrm{H}_{4} \mathrm{NH}_{3}\right)_{2} \mathrm{PbCl}_{4}$ back to structural features including the formation of hydrogen bonds. The optical properties of $\left(\mathrm{FC}_{2} \mathrm{H}_{4} \mathrm{NH}_{3}\right)_{2} \mathrm{PbCl}_{4}$ were characterized by optical absorption spectroscopy and time resolved photoluminescence measurements with a view toward the interaction between the organic and inorganic sublattices. The broad photoluminescence spectrum as well as specific absorption characteristics are assigned to exciton self trapping due to a strong coupling of the excited states to lattice distortions.
\end{abstract}

\section{INTRODUCTION}

Research in the field of hybrid perovskites has experienced a rapid revival since the discovery of the superior optical and electronic properties of methylammonium lead iodide (MAPI) as an absorber material in solar cells. Its large absorption coefficient, ${ }^{1}$ medium band gap, ${ }^{2}$ and long hole and electron diffusion lengths, ${ }^{3}$ combined with its solution processability, accelerated the development into one of the most important semiconductor materials for solid state solar cells. ${ }^{4}$ On the way to commercialization of hybrid perovskite solar cells, some challenges still have to be addressed, including the toxicity of lead and the poor moisture stability of MAPI type hybrid perovskites. ${ }^{5}$ Recently, Smith et al. reported a promising strategy to increase the moisture resistivity of MAPI derived compounds significantly. They separated the 3D lead iodide lattice by inserting bulky phenethylammonium cations (PEA) in the fashion of Mitzi's tin based hybrid perovskites, namely, $\left(\mathrm{C}_{4} \mathrm{H}_{9} \mathrm{NH}_{3}\right)_{2}\left(\mathrm{CH}_{3} \mathrm{NH}_{3}\right)_{n-1} \mathrm{Sn}_{n} \mathrm{I}_{3 n+1} \quad(n=$ number of corner sharing $\mathrm{SnI}_{6}$ octahedra forming the perovskite block), where butylammonium cations isolated the conducting perovskite layers to form a $2 \mathrm{D}$ quantum well type structure. ${ }^{6}$ Upon exposure of the as obtained (PEA) $2(\mathrm{MA})_{2}\left[\mathrm{~Pb}_{3} \mathrm{I}_{10}\right]\left(\mathrm{CH}_{3} \mathrm{NH}_{3}{ }^{+}\right.$ = MA) to a moist atmosphere, no degradation was observed. This is a testament to the higher stability inherent to many $2 \mathrm{D}$ perovkites and at the same time allows for the fabrication of high quality thin films, without sacrificing too much of the inherent optoelectronic properties of MAPI's 3D structure. ${ }^{7,8}$ Kanatzidis and co workers explored this concept for the $\left(\mathrm{CH}_{3}\left(\mathrm{CH}_{2}\right)_{3} \mathrm{NH}_{3}\right)_{2}\left(\mathrm{CH}_{3} \mathrm{NH}_{3}\right)_{n-1} \mathrm{~Pb}_{n} \mathrm{I}_{3 n+1}$ series and coined the terms perovskitizer and spacer for the cations forming the hybrid perovskite structure and those separating the quasi $3 \mathrm{D}$ perov skite blocks, respectively. Increasing the moisture resistivity is

Received: May 27, 2016

Revised: August 28, 2016

Published: August 29, 2016 
not the only benefit of including bulky organic cations in the structure; it also presents a synthetic tool for precisely tailoring the optical and electronic properties by the choice of the spacer cation and the number of layers in the perovskite blocks.9

A useful empirical guide for the search of suitable new perovskitizers and spacers is Goldschmidt's tolerance factor $t$, which determines the range of existence of the $3 \mathrm{D}$ perovskite structure $\mathrm{ABX}_{3}$ based on the radius ratio of the constituents $\mathrm{A}, \mathrm{B}$, and X. $t$ is determined by the following equation: ${ }^{10}$

$$
t=\left(r_{\mathrm{A}}+r_{\mathrm{X}}\right) / \sqrt{2}\left(r_{\mathrm{B}}+r_{\mathrm{X}}\right)
$$

A cubic perovskite structure can be expected, if $t$ is in the range 0.9-1.0. Additionally, distorted perovskite structures are likely to form for values from 0.80 to $0.89 .{ }^{11}\left(\mathrm{CH}_{3} \mathrm{CH}_{2} \mathrm{NH}_{3}\right) \mathrm{PbI}_{3}$, which seems to be very similar to MAPI at first sight, contains one dimensional (1D) face sharing $\mathrm{PbI}_{6}$ octahedral chains. ${ }^{12}$ The different structures become comprehensible, when taking the tolerance factor, which was calculated to be 1.05(4) by Kieslich et al., into account. ${ }^{11}$ Thus, cations which have at least the size of an ethylammonium cation are likely to be suitable candidates as spacers.

It is widely known that exchanging hydrogen atoms by fluorine atoms in hydrocarbons increases its hydrophobicity im mensely. ${ }^{13}$ Thus, applying fluorinated cations as spacers in hybrid perovskites would be a natural choice to further increase the moisture resistivity while potentially increasing the polarity at the same time. Furthermore, the studies by Frost et al. strongly suggest that increasing the dipole moment of the chosen organic cation could improve charge separation and increase carrier lifetimes due to an enhanced polarization of the crystal lattice, resulting in well separated "ferroelectric highways" for both charge carriers. ${ }^{14}$ For these reasons, an investigation of fluorinated A site cations is the next step for developing new potentially ferroelectric $2 \mathrm{D}$ hybrid perovskites with further enhanced moisture resistance.

In this work a new two dimensional (2D) hybrid perovskite, $\left(\mathrm{FC}_{2} \mathrm{H}_{4} \mathrm{NH}_{3}\right)_{2} \mathrm{PbCl}_{4}$, was synthesized, and its structural, thermal, and optical properties were investigated. The formation of a $2 \mathrm{D}$ structure indicates the ability of fluoroethylammonium to act as a spacer for MAPI based compounds. Exposure to ambient atmosphere for several months did not have any effect on the compound's integrity. Additionally, the crystal structure of the related DMF solvate $\left(\mathrm{FC}_{2} \mathrm{H}_{4} \mathrm{NH}_{3}\right) \mathrm{PbBr}_{3}$. DMF was determined, showing a transition from the $2 \mathrm{D}$ structure in $\left(\mathrm{FC}_{2} \mathrm{H}_{4} \mathrm{NH}_{3}\right)_{2}$ $\mathrm{PbCl}_{4}$ to a $1 \mathrm{D}$ chain like structure in $\left(\mathrm{FC}_{2} \mathrm{H}_{4} \mathrm{NH}_{3}\right) \mathrm{PbBr}_{3}$. DMF.

\section{EXPERIMENTAL SECTION}

Materials and Methods. $\mathrm{PbCl}_{2}$ (Sigma Aldrich, 98\%), $\mathrm{PbBr}_{2}$ (Sigma Aldrich, $\geq 98 \%$ ), 2 fluoroethylamine hydrochloride (Sigma Aldrich, 90\%), concentrated hydrochloric acid (Brenntag, purum), concentrated hydrobromic acid (Acros Organics, pure), and dimethyl formamide (Alfa Aesar, 99\%) were commercially available and used as received without further purification.

Synthesis of $\mathrm{FC}_{2} \mathrm{H}_{4} \mathrm{NH}_{3} \mathrm{Cl}$ and $\mathrm{FC}_{2} \mathrm{H}_{4} \mathrm{NH}_{3} \mathrm{Br} .1 .16 \times 10^{-1} \mathrm{~mL}(1.36$ $\mathrm{mmol})$ concentrated $\mathrm{HCl}$ or $1.55 \times 10^{-1} \mathrm{~mL}(1.36 \mathrm{mmol})$ concentrated $\mathrm{HBr}$ were added to $150 \mathrm{mg}(1.36 \mathrm{mmol})$ of 2 fluoroethylamine hydrochloride while cooling with an ice bath, respectively. The reaction mixture was stirred for $2.5 \mathrm{~h}$ at $0{ }^{\circ} \mathrm{C}$. The solvent was subsequently removed by heating to $50{ }^{\circ} \mathrm{C}$ under nitrogen flow. The yellowish product was washed with ether until a white color was obtained. Anal. Calcd for $\mathrm{FC}_{2} \mathrm{H}_{4} \mathrm{NH}_{3} \mathrm{Cl}$ : C, 24.13; $\mathrm{H}, 7.09 ; \mathrm{N}, 14.07$ wt \%. Found: C, 21.20; H, 7.11; N, 5.53 wt \%. IR ( $\left.\mathrm{cm}^{-1}\right): 3000(\mathrm{~m}), 2969(\mathrm{~m}), 2893(\mathrm{~m})$, 2822(m), 2768(m), 2679(m), 2634(m), 2482(w), 2013(w), $1607(\mathrm{~m})$, 1513(m), 1455(w), 1401(w), 1361(w), 1325(w), 1272(w), 1178(w), 1133(w), 1066(m), 994(s), 977(s), 876(w), 825(w). ${ }^{1} \mathrm{H}$ NMR $\left(\right.$ DMSO $\left.d_{6}, 20{ }^{\circ} \mathrm{C}\right) \delta=8.43\left(\mathrm{~s}, 3 \mathrm{H},-\mathrm{NH}_{3}\right), 4.66\left(\mathrm{~d}_{\mathrm{t}}, 2 \mathrm{H}, \mathrm{F}-\mathrm{CH}_{2}\right)$, $3.12\left(\mathrm{~d}_{\mathrm{v}}, 2 \mathrm{H}, \mathrm{H}_{3} \mathrm{~N}-\mathrm{CH}_{2}\right)$ ppm. ${ }^{13} \mathrm{C} \mathrm{NMR}\left(\mathrm{DMSO} d_{6}, 20{ }^{\circ} \mathrm{C}\right) \delta=80.5$ $\left(\mathrm{d}, \mathrm{F}-\mathrm{CH}_{2}\right), 39.1\left(\mathrm{~d}, \mathrm{H}_{3} \mathrm{~N}-\mathrm{CH}_{2}\right)$ ppm. Anal. Calcd for $\mathrm{FC}_{2} \mathrm{H}_{4} \mathrm{NH}_{3} \mathrm{Br}$ : C, $16.68 ; \mathrm{H}, 4.90 ; \mathrm{N}, 9.73 \mathrm{wt} \%$. Found: C, $15.24 ; \mathrm{H}, 4.81 ; \mathrm{N}, 10.16 \mathrm{wt} \%$. IR $\left(\mathrm{cm}^{-1}\right): 3095(\mathrm{~m}), 3015(\mathrm{~m}), 2925(\mathrm{~m}), 2796(\mathrm{~m}), 2666(\mathrm{w}), 2616(\mathrm{w})$, 2456(w), 2362(w), 2331(w), 1579(m), 1562(m), 1510(m), 1448(w), 1435(w), 1396(m), 1304(w), 1269(w), 1168(w), 1121(w), 1067(m), 983(s), 951(s), 870(m), 669(w). ${ }^{1} \mathrm{H}$ NMR (DMSO $\left.d_{6}, 20{ }^{\circ} \mathrm{C}\right) \delta=8.01$ $\left(\mathrm{s}, 3 \mathrm{H},-\mathrm{NH}_{3}\right), 4.64\left(\mathrm{~d}_{\mathrm{t}}, 2 \mathrm{H}, \mathrm{F}-\mathrm{CH}_{2}\right), 3.17\left(\mathrm{~d}_{\mathrm{t}}, 2 \mathrm{H}, \mathrm{H}_{3} \mathrm{~N}-\mathrm{CH}_{2}\right) \mathrm{ppm}$. ${ }^{13} \mathrm{C}$ NMR (DMSO $\left.d_{6}, 20{ }^{\circ} \mathrm{C}\right) \delta=80.6\left(\mathrm{~d}, \mathrm{~F}-\mathrm{CH}_{2}\right), 39.3\left(\mathrm{~d}, \mathrm{H}_{3} \mathrm{~N}-\right.$ $\mathrm{CH}_{2}$ ) ppm.

Synthesis of $\left(\mathrm{FC}_{2} \mathrm{H}_{4} \mathrm{NH}_{3}\right)_{2} \mathrm{PbCl}_{4} \cdot 71.5 \mathrm{mg}(0.72 \mathrm{mmol})$ $\mathrm{FC}_{2} \mathrm{H}_{4} \mathrm{NH}_{3} \mathrm{Cl}, 102.0 \mathrm{mg}(0.36 \mathrm{mmol}) \mathrm{PbCl}_{2}$, and $1.2 \mathrm{~mL}$ DMF were heated to $80^{\circ} \mathrm{C}$ for $2 \mathrm{~h}$, whereupon the solids were dissolved completely. Single crystals suitable for $\mathrm{X}$ ray diffraction analysis were obtained by evaporating the solvent at room temperature.

Synthesis of $\left(\mathrm{FC}_{2} \mathrm{H}_{4} \mathrm{NH}_{3}\right) \mathrm{PbBr}_{3} \cdot \mathrm{DMF}$. $28.8 \mathrm{mg}(0.2 \mathrm{mmol})$ $\mathrm{FC}_{2} \mathrm{H}_{4} \mathrm{NH}_{3} \mathrm{Br}, 74.9 \mathrm{mg}(0.2 \mathrm{mmol}) \mathrm{PbBr}_{2}$, and $1.0 \mathrm{~mL}$ DMF were heated to $80^{\circ} \mathrm{C}$ for $2 \mathrm{~h}$, whereupon the solids were dissolved completely. Single crystals suitable for $\mathrm{X}$ ray diffraction analysis were obtained by evaporating the solvent at room temperature.

Characterization. Single crystal $\mathrm{X}$ ray diffraction data of $\left(\mathrm{FC}_{2} \mathrm{H}_{4} \mathrm{NH}_{3}\right)_{2} \mathrm{PbCl}_{4}$ were collected at $-100{ }^{\circ} \mathrm{C}$ on a Bruker D8 Venture diffractometer equipped with a rotating anode generator with Mo $\mathrm{K}_{\alpha}$ radiation $(\lambda=0.71073 \AA)$. The diffraction intensities were integrated using the SAINT software package, and a multiscan absorption correction was applied with SADABS. The crystal structure was solved by direct methods (SIR97) ${ }^{15}$ and refined against $F^{2}$ by applying the full matrix least squares method (SHELXL 97) ${ }^{16,17} \mathrm{C}$ bound hydrogen positions were calculated according to geometrical criteria and treated as riding on their parent atoms while $\mathrm{N}$ bound hydrogen atoms were refined freely. All non hydrogen atoms were refined anisotropically.

Powder $\mathrm{X}$ ray diffraction (PXRD) patterns of $\left(\mathrm{FC}_{2} \mathrm{H}_{4} \mathrm{NH}_{3}\right)_{2} \mathrm{PbCl}_{4}$ were collected at various temperatures using a Bruker D8 Advance diffractometer in Debye-Scherrer geometry with a Våntec detector with $\mathrm{Ge}(111)$ monochromated $\mathrm{Cu} \mathrm{K} \mathrm{K}_{\alpha 1}$ radiation $(\lambda=1.54059 \AA)$. The sample was encapsulated in a capillary under inert atmosphere; nonetheless, air stability was confirmed thereafter. For further PXRD measurements at room temperature, a Huber G670 Guinier imaging plate detector in transmission geometry was used. These measurements were also performed with $\mathrm{Ge}(111)$ monochromated $\mathrm{Cu} \mathrm{K}_{\alpha 1}$ radiation $(\lambda=1.54059 \AA)$. Full profile fits were obtained using TOPAS Academic. $^{18}$

Solid state NMR sprectra were recorded on a Bruker Avance III WB $400 \mathrm{MHz}\left(H_{0}=9.4 \mathrm{~T}\right)$ instrument. A Bruker douple resonance BL4MAS probe and $4 \mathrm{~mm}$ zirconia rotors were used for all measurements. ${ }^{13} \mathrm{C}$ and ${ }^{1} \mathrm{H}$ spectra were referenced to the customary standard tetramethylsilane (TMS), using the high frequency signal of solid adamantane at $38.56 \mathrm{ppm}$ as a secondary standard in ${ }^{13} \mathrm{C}$ spectra and the signal at $1.74 \mathrm{ppm}$ in ${ }^{1} \mathrm{H}$ spectra. In experiments with magic angle spinning (MAS), the sample was spun between 8000 and 12500 $\mathrm{Hz}$, with the spinning rate controlled by the standard Bruker equipment. The ${ }^{1} \mathrm{H}$ spectra were acquired in 16 scans with a relaxation delay of $3 \mathrm{~s}$. The ${ }^{13} \mathrm{C}$ cross polarization (CP) MAS spectra were recorded in 1024 scans with a contact time of $4 \mathrm{~ms}$ and a recyle delay of $1 \mathrm{~s} . \mathrm{All}^{13} \mathrm{C}$ and ${ }^{207} \mathrm{~Pb}$ spectra were acquired with high power proton decoupling that was achieved using the SPINAL 64 decoupling method. ${ }^{207} \mathrm{~Pb}$ spectra were referenced to tetramethyl lead $(\delta=0.0 \mathrm{ppm})$ with the solid $\mathrm{Pb}\left(\mathrm{NO}_{3}\right)_{2}$ as a secondary standard $\left(\delta=-3494 \mathrm{ppm}\right.$ at $20^{\circ} \mathrm{C}$ and MAS of $\left.1500 \mathrm{~Hz}\right)$. ${ }^{207} \mathrm{~Pb}$ MAS spectra were recorded with rotor synchronized $\mathrm{Hahn}$ echo. The sample was spun at $8000 \mathrm{~Hz}$ for the measurement at $85^{\circ} \mathrm{C}$ and at $10000 \mathrm{~Hz}$ for all of the other measurements. The repetition time was set to $4 \mathrm{~s}$, and the number of scans was 2048 .

Differential scanning calorimetry (DSC) data was collected using a Linseis PT 10 calorimeter. Samples were heated in sealed aluminum pans under air from room temperature to $125^{\circ} \mathrm{C}$ with a heating rate of $3 \mathrm{~K}$ $\mathrm{min}^{-1}$ and subsequently cooled down to room temperature at the same rate. Additionaly, DSC measurements were performed using a 
PerkinElmer Pyris 1 . The sample was heated from -46 to $195^{\circ} \mathrm{C}$ with a heating rate of $3 \mathrm{~K} \mathrm{~min}^{-1}$ and subsequently cooled down to room temperature at the same rate.

Optical samples were prepared by clamping $\left(\mathrm{FC}_{2} \mathrm{H}_{4} \mathrm{NH}_{3}\right)_{2} \mathrm{PbCl}_{4}$ powder between two quartz glass substrates. Absorption spectra were recorded with an Agilent Technologies 8453 UV-vis spectrometer in an integrating sphere. For steady state and time resolved photolumines cence measurements, a PicoQuant FluoTime 300 fluorescence spectrometer was used. Steady state photoluminescence was measured using a $300 \mathrm{~W}$ xenon arc lamp. The excitation source for time resolved photoluminescence measurements was a picosecond pulsed laser diode of $405 \mathrm{~nm}$, and the decay was recorded on the basis of time correlated single photon counting.

FTIR spectra were recorded at ambient conditions between 650 and $4000 \mathrm{~cm}^{-1}$ on a Spektrum BX II FTIR spectrometer (PerkinElmer) equipped with a DuraSampler diamond ATR device.

Elemental analyses for $\mathrm{C}, \mathrm{H}$, and $\mathrm{N}$ were performed with the elemental analyzer systems Vario EL and Vario Micro (Elementar Analysensysteme $\mathrm{GmbH}$ ).

Electronic structure calculations were performed in the framework of density functional theory (DFT) using the Wien $2 \mathrm{k}^{19}$ code with a full potential linearized augmented planewave and local orbitals [FP LAPW + lo] basis $^{20-22}$ together with the Perdew-Burke-Ernzerhof (PBE) parametrization $^{23}$ of the generalized approximation (GGA) as the exchange correlation functional. Spin-orbit coupling was included. The plane wave cutoff parameter $\mathrm{R}_{\mathrm{MT}} \mathrm{K}_{\max }$ was set to 7 , and the irreducible Brillouin zone was sampled by $147 \mathrm{k}$ points.

\section{RESULTS AND DISCUSSION}

Structural Investigation of $\left(\mathrm{FC}_{2} \mathrm{H}_{4} \mathrm{NH}_{3}\right)_{2} \mathrm{PbCl}_{4}$. The stoichiometric reaction of $\mathrm{PbCl}_{2}$ and 2 fluoroethylammonium chloride in DMF led to phase pure $\left(\mathrm{FC}_{2} \mathrm{H}_{4} \mathrm{NH}_{3}\right)_{2} \mathrm{PbCl}_{4}$. The crystal structure of the $2 \mathrm{D}$ organic-inorganic perovskite $\left(\mathrm{FC}_{2} \mathrm{H}_{4} \mathrm{NH}_{3}\right)_{2} \mathrm{PbCl}_{4}$ was determined by single crystal $\mathrm{X}$ ray diffraction at $173 \mathrm{~K}$. Crystallographic data and details of the structure refinement are shown in Tables SI-SV. The compound crystallizes in a layered $2 \mathrm{D}$ perovskite type structure akin to halide representatives of the Ruddlesden-Popper phases with $n$ $=1$, where $n$ is the number of corner sharing octahedral layers in the perovskite blocks $\left[\mathrm{ABX}_{3}\right]_{n}$, interleaved with $n[\mathrm{AX}]$ blocks with rock salt type structure. $\left(\mathrm{FC}_{2} \mathrm{H}_{4} \mathrm{NH}_{3}\right)_{2} \mathrm{PbCl}_{4}$ comprises layers of trans connected, corner sharing $\mathrm{PbCl}_{6}$ octahedra, which are severely distorted (Figure 1). Possible reasons for this

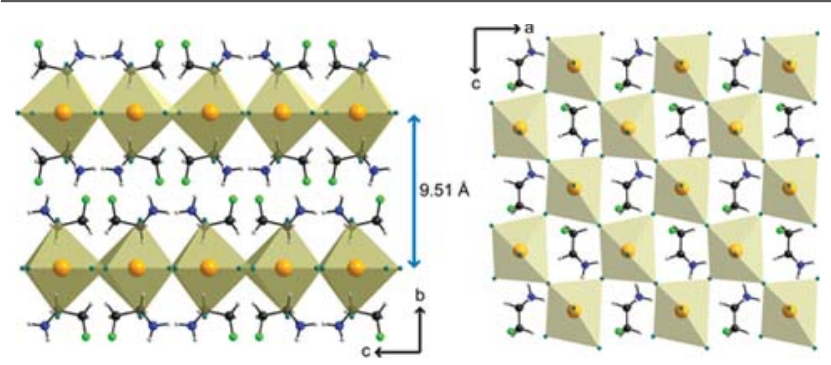

Figure 1. Crystal structure of $\left(\mathrm{FC}_{2} \mathrm{H}_{4} \mathrm{NH}_{3}\right)_{2} \mathrm{PbCl}_{4}$ in projection along [100] (left) and in projection along [010] (right). $\mathrm{C}$ is displayed in black, $\mathrm{N}$ is blue, $\mathrm{F}$ is green, $\mathrm{H}$ is gray, $\mathrm{Pb}$ is orange, and $\mathrm{Cl}$ is turquoise.

distortion will be discussed in detail later on. The organic cations form a double layer which is stabilized by weak intermolecular hydrogen bonds. ${ }^{24}$ Intramolecular hydrogen bonds between the fluorine substituents and the protonated amine groups lead to the observed cis configuration of the 2 fluoroethylammonium cations (Table SVI). The distance between the $\mathrm{PbCl}_{4}{ }^{2-}$ layers was determined to be $9.51 \AA$. $\left(\mathrm{FC}_{2} \mathrm{H}_{4} \mathrm{NH}_{3}\right)_{2} \mathrm{PbCl}_{4}$ exhibits Pnma symmetry. Due to the centrosymmetric nature of the space group, ferroelectric properties cannot be expected for $\left(\mathrm{FC}_{2} \mathrm{H}_{4} \mathrm{NH}_{3}\right)_{2} \mathrm{PbCl}_{4}$.

In contrast to the chloride version discussed above, the reaction of fluoroethylammonium bromide with lead bromide in DMF leads to the formation of a dimensionally reduced DMF solvate in which the $2 \mathrm{D}$ lead bromide layers are broken up into 1D double chains consisting of edge sharing octahedra. A discussion of the crystal structure of the resulting compound, $\left(\mathrm{FC}_{2} \mathrm{H}_{4} \mathrm{NH}_{3}\right) \mathrm{PbBr}_{3} \cdot \mathrm{DMF}$, and additional experimental details can be found in the Supporting Information S8-S12.

DFT Calculations. The $\mathrm{PbCl}_{6}$ octahedra in $\left(\mathrm{FC}_{2} \mathrm{H}_{4} \mathrm{NH}_{3}\right)_{2}$ $\mathrm{PbCl}_{4}$ exhibit $\mathrm{Pb}-\mathrm{Cl}$ bond lengths between 2.7001(7) and 3.2054(7) $\AA$ and bond angles between $86.5^{\circ}$ and $93.9^{\circ}$ (Tables $\mathrm{SIV}$ and $\mathrm{SV})$. Related compounds reported in the literature, namely, $\left(\mathrm{C}_{3} \mathrm{H}_{7} \mathrm{NH}_{3}\right)_{2} \mathrm{PbCl}_{4}$ and $\left(\mathrm{C}_{6} \mathrm{H}_{5} \mathrm{C}_{2} \mathrm{H}_{4} \mathrm{NH}_{3}\right)_{2} \mathrm{PbCl}_{4}$, show a qualitatively similar, however much smaller, distortion of the $\mathrm{Pb}$ atom coordination sphere with $\mathrm{Pb}-\mathrm{Cl}$ bond lengths in the ranges $2.830(7)-2.899(7) \AA$ and $2.752(2)-3.033(2) \AA$, respective ly. ${ }^{25,26}$ In order to investigate the origin of this rather severe distortion present in $\left(\mathrm{FC}_{2} \mathrm{H}_{4} \mathrm{NH}_{3}\right)_{2} \mathrm{PbCl}_{4}$, electronic structure calculations on the DFT level including spin-orbit coupling were performed. If the origin was due to a sterically active $\mathrm{Pb} 6 \mathrm{~s}$ lone pair, we would expect to see hybridization between $\mathrm{s}$ and $\mathrm{p}$ states at the Fermi level. This hybridization would result in a stereochemically active lone pair that is not centrosymmetric and could therefore reside off center within an octahedron, causing distortion. Analysis of the partial density of states (PDOS) reveals that the valence band consists mostly of $\mathrm{Cl} 3 \mathrm{p}$ states, mixed with $\mathrm{Pb} 6 \mathrm{~s}$ and $\mathrm{Pb} 6 \mathrm{p}$ states. The $\mathrm{Pb} 6$ s states are found in the upper valence band whereas the $\mathrm{Pb} 6 \mathrm{p}$ states are located in the lower valence band. Additional $\mathrm{Pb} 6$ s states are localized below $-6 \mathrm{eV}$. The conduction band is dominated by $\mathrm{Pb} 6 \mathrm{p}$ states. Taking a closer look at the upper valence band, a small fraction of $6 \mathrm{p}$ states can be observed at the same energy level as 6 s states which allows for hybridization of these states (Figure 2a,b). This could suggest the presence of a steric effect of the lone pair that can follow from canceling out the centrosymmetry of the s orbital by adding $\mathrm{p}$ character. However, in our case this effect is presumably very small, since the density of $\mathrm{Pb} \mathrm{p}$ states in the upper valence band is below 0.014 states (formula unit) $)^{-1} \mathrm{eV}^{-1}$. Therefore, the octahedral distortions seem to be of structural rather than electronic origin, which becomes apparent when projecting the crystal structure down the $b$ axis (Figure 1). The size of the organic cations exactly matches the vacancies within the octahedral network; therefore, the octahedral distortion results in an optimal dense packing. Additionally, moderate and weak hydrogen bonds ${ }^{24}$ between the organic cations and the $\mathrm{Cl}$ atoms of the inorganic lattice might contribute to the observed structural distortions (Table SVI). The calculated bandgap is $2.51 \mathrm{eV}$ which is significantly lower than the measured band gap of $3.27 \mathrm{eV}$. The PBE functional used for our calculations is, however, well known to underestimate band gaps, and the discrepancy of $0.75 \mathrm{eV}$ is within the usual range of under estimation. The organic cations do not seem to have any influence on the band gap as an analysis of the respective states shows (Figure S2a). The band structure plot (Figure 2c) reveals the band gap to be indirect, with the valence band maximum located at $\Gamma$ and the conduction band minimum located between $\Gamma$ and $\mathrm{Z}$. Fat band plots also show the presence of $\mathrm{a} \mathrm{Pb} 6$ s lone pair (Figure S2b).

Phase Transitions in $\left(\mathrm{FC}_{2} \mathrm{H}_{4} \mathrm{NH}_{3}\right)_{2} \mathrm{PbCl}_{4}$. DSC measure ments indicate two reversible phase transitions at $87{ }^{\circ} \mathrm{C}$ and at $107^{\circ} \mathrm{C}$, which were determined from the heating cycle (Figure 
(a)

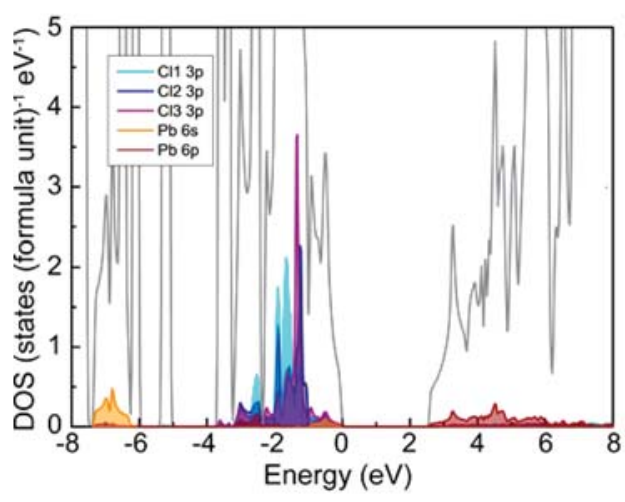

(b)

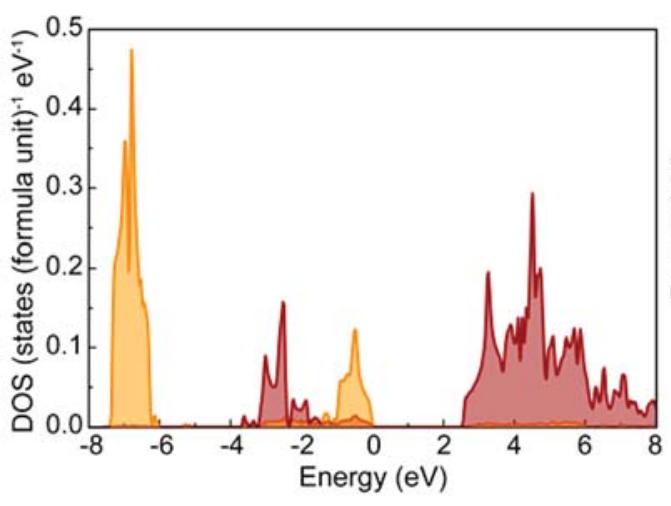

(c) 5

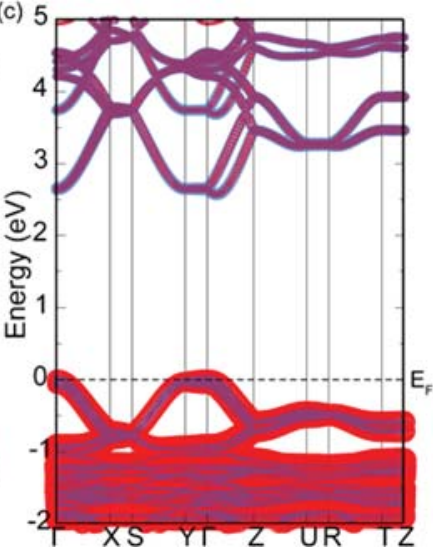

Figure 2. (a) Partial density of states (PDOS) plot for $\left(\mathrm{FC}_{2} \mathrm{H}_{4} \mathrm{NH}_{3}\right)_{2} \mathrm{PbCl}_{4}$, showing $3 \mathrm{p}$ states of the three different $\mathrm{Cl}$ sites as well as $\mathrm{Pb} 6 \mathrm{~s}$ and $6 \mathrm{p}$ states. The total DOS is plotted in gray in the background. The positions of the $\mathrm{Pb} 6 \mathrm{~s}$ and $6 \mathrm{p}$ states are highlighted in part $\mathrm{b}$. (c) Band structure of $\left(\mathrm{FC}_{2} \mathrm{H}_{4} \mathrm{NH}_{3}\right)_{2} \mathrm{PbCl}_{4}$. Contributions from $\mathrm{Cl}$ states are indicated in red, whereas $\mathrm{Pb}$ states are shown in blue (all orbitals). The overlay of the red and blue bands results in the color purple. The thickness of the bands is a measure for the contribution of those states.

S3). These were investigated more closely using solid state NMR spectroscopy. To probe both the effect of structural distortions and rearrangements in the organic and inorganic sublattices, the spectra of ${ }^{1} \mathrm{H},{ }^{13} \mathrm{C}$, and ${ }^{207} \mathrm{~Pb}$ were monitored. While $\left(\mathrm{FC}_{2} \mathrm{H}_{4} \mathrm{NH}_{3}\right)_{2} \mathrm{PbCl}_{4}$ was heated up to $112.5{ }^{\circ} \mathrm{C}$ followed by cooling down to room temperature, several ${ }^{207} \mathrm{~Pb}$ solid state NMR sprectra were recorded (Figure $3 b$ ). ${ }^{207} \mathrm{~Pb}$ is a spin $1 / 2$
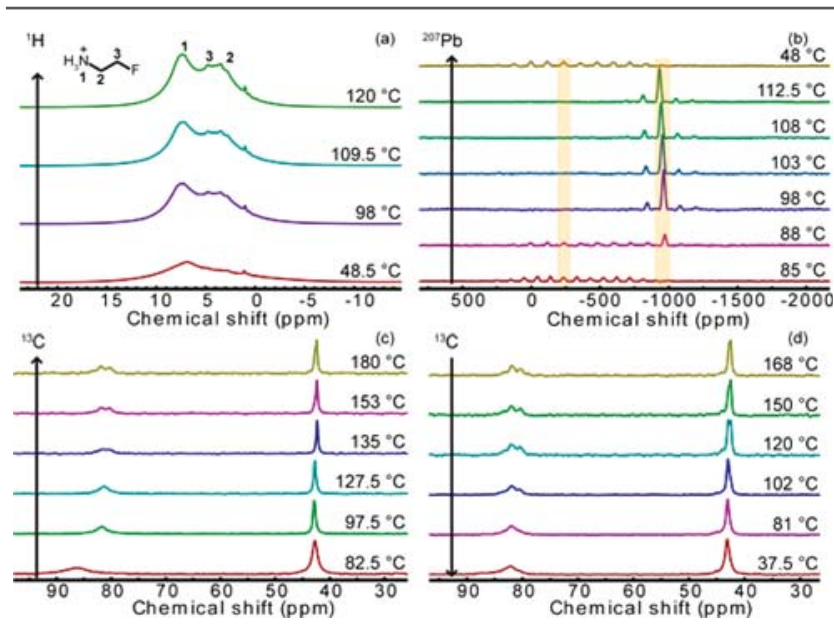

Figure 3. (a) ${ }^{1} \mathrm{H}$ MAS, (b) ${ }^{207} \mathrm{~Pb}$ MAS, and (c, d) ${ }^{13} \mathrm{C} \mathrm{CP}$ MAS solid state NMR spectra of $\left(\mathrm{FC}_{2} \mathrm{H}_{4} \mathrm{NH}_{3}\right)_{2} \mathrm{PbCl}_{4}$. The arrows indicate the course of the temperature program. The isotropic signals are highlighted for the ${ }^{207} \mathrm{~Pb}$ NMR spectra. The remaining signals (b) are spinning side bands.

nucleus with an extremely wide chemical shift range, with $\mathrm{Pb}$ (II) covering a range between 3000 and $-6000 \mathrm{ppm}$. The observed chemical shifts are in agreement with the oxidation state $\mathrm{Pb}(\mathrm{II})$, while the highly anisotropic shape of the signal observed below the first phase transition points to an asymmetrical coordination sphere of the $\mathrm{Pb}$ atoms. This observation is in accordance with the above described severely distorted $\mathrm{PbCl}_{6}$ octahedra. The first phase transition is therefore most likely connected to a change in the inorganic sublattice producing a more symmetrical lead environment, and accompanied by a substantially reduced anisotropy and a shift of the signal from $-237 \pm 2 \mathrm{ppm}$ to $-971 \pm 2 \mathrm{ppm}$. These changes are found to be reversible upon cooling the sample down to room temperature. Apart from a small downfield shift, the second phase transition is not observed in the ${ }^{207} \mathrm{~Pb}$ spectrum, which essentially excludes an involvement of the $\mathrm{Pb}-\mathrm{Cl}$ lattice in the phase transition. Presumably, the second phase transition is related to small changes in the mobility or orientation of the A site cation. ${ }^{1} \mathrm{H}$ solid state NMR sprectra show three overlapping signals that can be assigned to the protons of the $\mathrm{NH}_{3}$ group and the two methylene groups, respectively (Figure $3 \mathrm{a}$ ). The assignment is based on the relative integrated intensities, and expected relative shifts in ${ }^{1} \mathrm{H}$ resonances of $-\mathrm{CH}_{2}-$ and $-\mathrm{CH}_{2} \mathrm{~F}$ signals. The first phase transition leads to a downfield shift and a narrowing of the observed signals, which supports the assumption that the 2 fluorethylammonium cations become more mobile due to the change in the heavy lattice. As a consequence, they can rotate more freely. The second phase transition does not have a visible fingerprint in the ${ }^{1} \mathrm{H}$ NMR spectra. Finally, a temperature dependent structural investigation using ${ }^{13} \mathrm{C}$ solid state $\mathrm{NMR}$ spectroscopy was performed (Figure $3 \mathrm{c}, \mathrm{d}$ ). The recorded ${ }^{13} \mathrm{C}$ solid state NMR spectra show two distinct signals which are assigned to the carbon atoms of the methylene groups. Upon heating the sample above the first transition temperature, a narrowing of the signals can be observed besides a significant upfield shift of the signal detected at $86.4 \mathrm{ppm}$. This signal splits up into two when the temperature is increased above $127.5^{\circ} \mathrm{C}$. It is conceivable that this signature at $127.5^{\circ} \mathrm{C}$ is associated with a delayed second phase transition which is seen at $107^{\circ} \mathrm{C}$ in the DSC measurements. A possible reason for the splitting is the direct spin-spin $J$ coupling between adjacent $\mathrm{F}$ and $\mathrm{C}$ atoms. However, the doublet should be more distinct in this case. Therefore, it is most likely that what we see is not entirely due to ${ }^{19} \mathrm{~F}-{ }^{13} \mathrm{C} J$ coupling, but also due to melting of the organic sublattice above the transition temperature, giving rise to dynamical disorder of the organic cations. The signal at 42.4 ppm starts splitting up only at $180{ }^{\circ} \mathrm{C}$. These later changes are partly reversible upon cooling down and are not distinctly related to either of the structural phase transitions. The changes associated with the first phase transition, however, are persistent. To summarize, heating $\left(\mathrm{FC}_{2} \mathrm{H}_{4} \mathrm{NH}_{3}\right)_{2} \mathrm{PbCl}_{4}$ above $130{ }^{\circ} \mathrm{C}$ leads to a permanent structural change, but the compound is not decomposed upon heating it up to $180^{\circ} \mathrm{C}$.

Powder X-ray Diffraction (PXRD). PXRD was used to complement the above described insights into the reversibility and local structural changes during the temperature dependent 

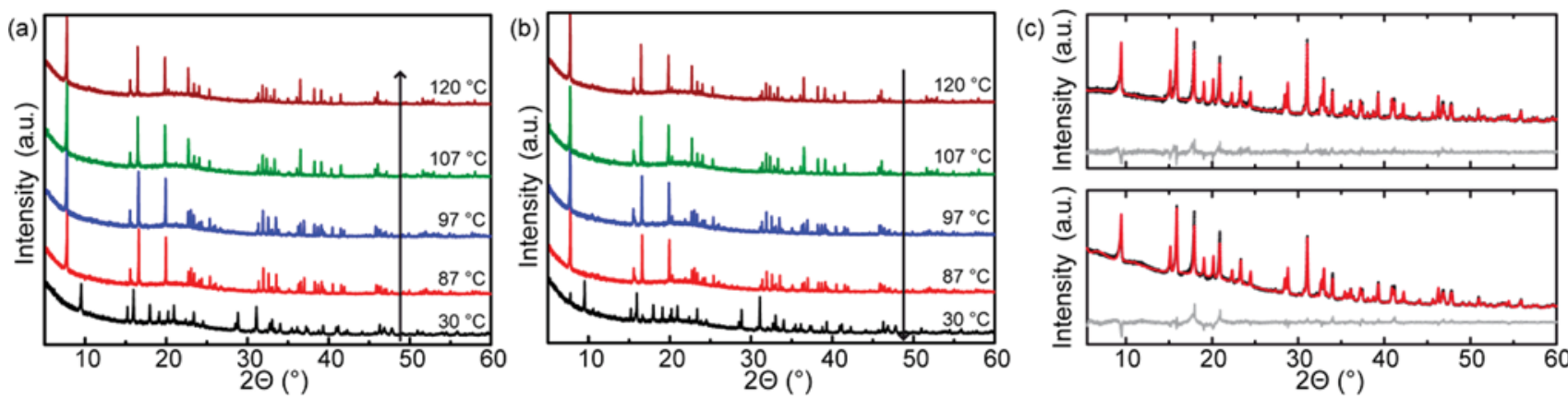

Figure 4. Powder $\mathrm{X}$ ray diffraction patterns monitoring the phase transitions upon (a) heating the sample to $120^{\circ} \mathrm{C}$ and (b) cooling the sample back down to $30^{\circ} \mathrm{C}$. $\mathrm{X}$ ray powder diffraction data of $\left(\mathrm{FC}_{2} \mathrm{H}_{4} \mathrm{NH}_{3}\right)_{2} \mathrm{PbCl}_{4}$ acquired at room temperature right after synthesis (bottom) and after 4 months exposure to ambient conditions (top) represented by open circles. (c) Rietveld profile fits (red solid lines) confirm phase purity. The difference curves are displayed in gray.

(a)

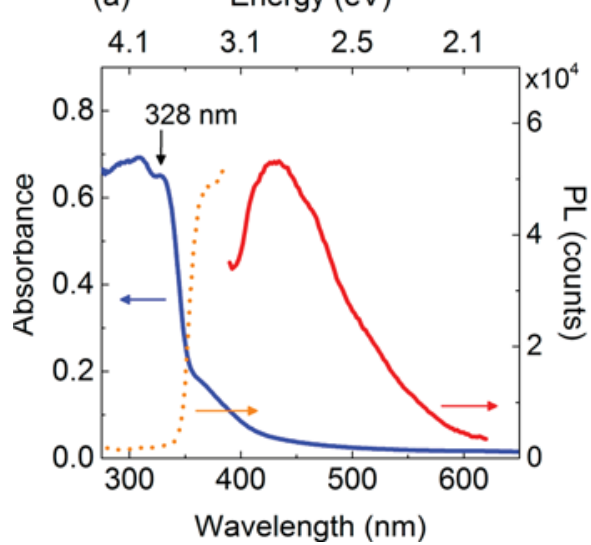

(b)

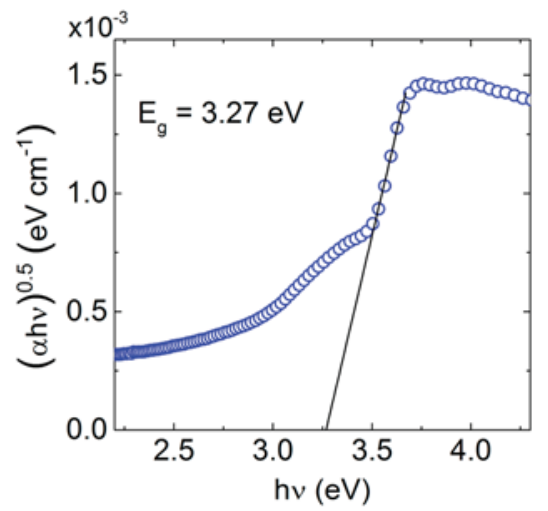

(c)

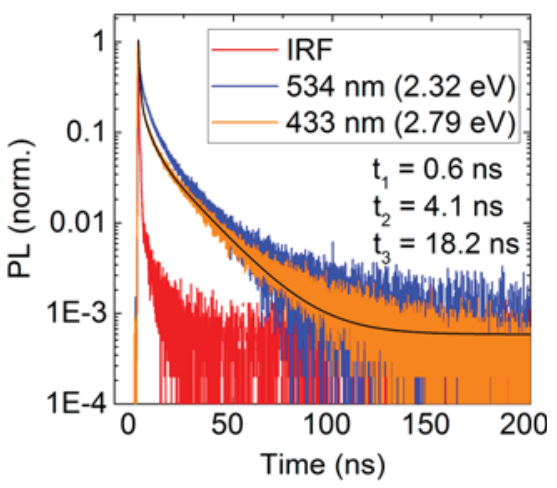

Figure 5. (a) Absorbance (blue solid line), photoluminescence (red solid line, $\lambda_{\text {excitation }}=375 \mathrm{~nm}$ ), and photoluminescence excitation spectrum (orange dots, $\lambda_{\text {emission }}=443 \mathrm{~nm}$ ) of $\left(\mathrm{FC}_{2} \mathrm{H}_{4} \mathrm{NH}_{3}\right)_{2} \mathrm{PbCl}_{4}$ at $295 \mathrm{~K}$. (b) Tauc plot with an indirect band gap of $3.27 \mathrm{eV}$. (c) PL decay of $\left(\mathrm{FC}_{2} \mathrm{H}_{4} \mathrm{NH}_{3}\right)_{2} \mathrm{PbCl}_{4}$ at different emission energies at $295 \mathrm{~K}$ and the instrument response function (IRF). The PL decay at $2.79 \mathrm{eV}$ is fitted with a three exponential decay function (black line).

structural phase transitions of $\left(\mathrm{FC}_{2} \mathrm{H}_{4} \mathrm{NH}_{3}\right)_{2} \mathrm{PbCl}_{4}$ (Figure $4 a, b)$. The structural change connected to the first phase transition becomes obvious on comparing the dissimilar diffractograms recorded at 30 and $87^{\circ} \mathrm{C}$. Only small additional changes can be observed when the sample is heated to $120^{\circ} \mathrm{C}$, which consolidates the assumption that the second phase transition is not connected to any significant structural changes in the inorganic sublattice. When cooling the sample back down to $30^{\circ} \mathrm{C}$, the initial diffractogram recorded at $30^{\circ} \mathrm{C}$ is regained almost completely. Only the reflection at $7.75^{\circ}$ which is very prominent in the diffractograms of the high temperature phase has not vanished completely despite a significant loss in intensity. Recording another diffractogram of the sample 1 year after conducting the heating cycle shows that the phase transition is indeed fully reversible: the reflection at $7.75^{\circ}$ cannot be observed anymore (Figure S4). These results indicate that the conversion from the high temperature to the low temperature phase might be kinetically delayed.

Optical Properties. Absorption and photoluminescence measurements were performed to investigate the optical properties of $\left(\mathrm{FC}_{2} \mathrm{H}_{4} \mathrm{NH}_{3}\right)_{2} \mathrm{PbCl}_{4}$. The absorbance spectrum of $\left(\mathrm{FC}_{2} \mathrm{H}_{4} \mathrm{NH}_{3}\right)_{2} \mathrm{PbCl}_{4}$ is presented in Figure 5a. With the assumption of an indirect band gap (also confirmed by DFT calculations, see above), a band gap of $3.27 \mathrm{eV}$ is determined with a Tauc plot, which is comparable to other organic-inorganic layered perovskite compounds (Figure 5b). ${ }^{1,27,28}$ Typically, these layered perovskites feature a sharp excitonic absorption peak below the band edge, as the dielectric mismatch between organic and inorganic layer causes a high exciton binding energy and strongly bound excitons within the inorganic layer. ${ }^{27-29}$ As can be seen in Figure 5a, a clear separation between the absorption band edge and the excitonic peak for $\left(\mathrm{FC}_{2} \mathrm{H}_{4} \mathrm{NH}_{3}\right)_{2} \mathrm{PbCl}_{4}$ cannot be observed, but there is an overlap of a peak at $328 \mathrm{~nm}$ and the band edge. Such a close occurrence of an excitonic absorption peak and the band edge has already been reported for other organic-inorganic layered perovskite compounds $^{30}$ and can be explained by the fact that the optical properties strongly depend on the organic moiety. Possible effects of the organic layer on excited states within the inorganic layer include a change of the exciton binding energy depending on the organic layer's dielectric constant, a potential energy transfer into the organic layer, ${ }^{31}$ and structural distortions of the inorganic layer imposed by the organic layer. ${ }^{30,32,33}$ Con sequently, differences in optical properties for different organic-inorganic layered perovskite compounds can be expected. While for excitation above the bandgap, no significant photoluminescence can be detected (Figure S5a); excitation into the sub bandgap absorption feature between 350 and $400 \mathrm{~nm}$ leads to a strong and broad photoluminescence (PL) spectrum (Figure 5a). As the PL excitation spectrum for the PL emission peak at $443 \mathrm{~nm}$ coincides well with the sub bandgap absorption feature for wavelengths above $350 \mathrm{~nm}$, it can be assumed that 
excitation of these sub bandgap states leads to enhanced radiative recombination. The origin of such a broad emission has already been discussed by Dohner et al., ${ }^{28}$ who assigned the broad PL to strong coupling of excited states to lattice distortions and the inhomogeneous broadening of the PL spectrum to additional contributions of trap states. Similary, Papavassiliou et al. ${ }^{32}$ investigated the impact of the organic moiety on PL properties and found that organic layers consisting of short alkyl chains lead to a broad PL spectrum due to self trapped excitons, whereas longer alkyl chains lead to sharp excitonic PL peaks. These observations are consistent with the data presented here, as the crystal structure of $\left(\mathrm{FC}_{2} \mathrm{H}_{4} \mathrm{NH}_{3}\right)_{2} \mathrm{PbCl}_{4}$ features severe structural distortions of the inorganic sublattice at room temperature, which is assumed to induce self trapping of excitons due to a coupling to lattice distortions. Moreover, an impact of the fluorine in the organic moiety on the PL properties cannot be excluded either. The fact that the PL spectrum can be excited by excitation energies that are almost as small as the emission energy indicates a continuum of initial states that can contribute to the broad PL spectrum. Such a broad distribution of emitting states cannot be explained by a specific crystal defect, but rather by a continuous energy distribution of lattice distortions. The inhomogeneous broadening of the $\mathrm{PL}$ spectrum of $\left(\mathrm{FC}_{2} \mathrm{H}_{4} \mathrm{NH}_{3}\right)_{2} \mathrm{PbCl}_{4}$ can be fitted with two Gaussian functions with peak positions at 2.79 and $2.32 \mathrm{eV}$, respectively (Figure S6b). Both the lower energy shoulder and the broad PL emission can be excited by the same absorption features (Figure S5b) and have similar lifetimes (Figure 5c), suggesting the same physical nature of these states and thermal equilibrium between them. ${ }^{28}$ However, as Figure S6b displays an increase of the lower energy shoulder for a decrease in temperature, an enhanced trapping rate of excited states can be assumed for lower temperatures. The photoluminescence decay displayed in Figure $5 \mathrm{c}$ can be fitted with a three exponential decay function with lifetimes of $t_{1}=0.6$ $\mathrm{ns}, t_{2}=4 \mathrm{~ns}$, and $t_{3}=18 \mathrm{~ns}$. PL lifetimes of several nanoseconds are characteristic for organic-inorganic layered perovskites. ${ }^{28,33}$ In contrast to $3 \mathrm{D}$ organic-inorganic perovskites, where charge recombination of free electrons and holes determines the PL characteristics at room temperature, leading to lifetimes on the order of hundreds of nanoseconds, ${ }^{3,34}$ the PL of layered perovskites predominantly originates from confined excitons within the inorganic layer. On the basis of the multiexponential decay, it is suggested that several dynamical processes take place after photoexcitation, including the intrinsic lifetime of free excitons and the formation of self trapped excitons, as well as their interaction with interface states and potential permanent lattice defects, or intersystem crossing with triplet states. ${ }^{33,35}$

Stability. An important finding is that, in contrast to other 2D and $3 \mathrm{D}$ hybrid perovskites, $\left(\mathrm{FC}_{2} \mathrm{H}_{4} \mathrm{NH}_{3}\right)_{2} \mathrm{PbCl}_{4}$ shows pro nounced long term stability. When exposed to ambient conditions over several months, no visible changes can be observed. Rietveld analyses of PXRD data of $\left(\mathrm{FC}_{2} \mathrm{H}_{4} \mathrm{NH}_{3}\right)_{2}$ $\mathrm{PbCl}_{4}$ right after synthesis and after 4 months exposure confirm this observation (Figure $4 \mathrm{c}$ and Figure S2).

\section{CONCLUSION}

The crystal structures of the new hybrid compounds, $\left(\mathrm{FC}_{2} \mathrm{H}_{4} \mathrm{NH}_{3}\right)_{2} \mathrm{PbCl}_{4}$ and $\left(\mathrm{FC}_{2} \mathrm{H}_{4} \mathrm{NH}_{3}\right) \mathrm{PbBr}_{3} \cdot \mathrm{DMF}$, were dis cussed with a special focus on the influence of hydrogen bonds and the origin of structural distortions in the inorganic sublattice on the arrangement of the organic cations. Moreover, the phase transitions of $\left(\mathrm{FC}_{2} \mathrm{H}_{4} \mathrm{NH}_{3}\right)_{2} \mathrm{PbCl}_{4}$ were investigated closely by combining solid state NMR spectroscopy, DSC measurements, and PXRD. It could be shown that the first phase transition at 87 ${ }^{\circ} \mathrm{C}$ is due to structural changes in the heavy lattice whereas the second phase transition is likely related to orientational changes in the organic sublattice. DFT calculations suggested that the observed distortion of the $\mathrm{PbCl}_{6}$ octahedra predominantly is of structural origin connected to a dense packing of the organic cations and the inorganic lattice and the formation of hydrogen bonds between the inorganic and organic sublattice, rather than of electronic origin based on hybridization of the $\mathrm{Pb} 6$ s lone pair. Optical measurements were applied to study the nature of the photogenerated states and their interaction with the crystal lattice. A strong and broad PL spectrum for excitations below the bandgap is assigned to a coupling of excited states to lattice distortions. The resulting self trapped excitons lead to a temperature dependent inhomogeneous broadening of the PL spectrum and a multiexponential PL decay with lifetimes in the nanosecond range. Additionally, it was shown that $\left(\mathrm{FC}_{2} \mathrm{H}_{4} \mathrm{NH}_{3}\right)_{2} \mathrm{PbCl}_{4}$ features long term stability under ambient conditions. These findings suggest that the fluoroethylammo nium cation is a promising candidate as a spacer for moisture resistant MAPI derived compounds due to its ability to create 2 dimensional structures and the demonstrated stability of $\left(\mathrm{FC}_{2} \mathrm{H}_{4} \mathrm{NH}_{3}\right)_{2} \mathrm{PbCl}_{4}$. Synthesizing a compound that contains several layers of MAPI separated by layers of $\left(\mathrm{FC}_{2} \mathrm{H}_{4} \mathrm{NH}_{3}\right)^{+}$ might have the potential for combining the favorable optical properties of MAPI with the better stability of a $2 \mathrm{D}$ hybrid perovskite. Additionally, $\left(\mathrm{FC}_{2} \mathrm{H}_{4} \mathrm{NH}_{3}\right)^{+}$features a large dipole moment which might lead to an enhanced polarity of the lattice and with it an increase in charge separation and improved carrier lifetimes as theoretical studies by Frost et al. indicate. ${ }^{14}$ These factors point to a number of design criteria which when synergistically combined may give rise to powerful absorber materials for solar cells and related optoelectronic devices.

\section{ASSOCIATED CONTENT}

\section{Supporting Information}

The Supporting Information is available free of charge on the ACS Publications website at DOI: 10.1021/acs.chemma ter.6b02151.

Crystallographic data, DSC data, additional band structure and PDOS plots, additional PXRD data, PL and PL excitation spectra, and a discussion of the crystal structure of $\left(\mathrm{FC}_{2} \mathrm{H}_{4} \mathrm{NH}_{3}\right) \mathrm{PbBr}_{3} \cdot \mathrm{DMF}(\mathrm{PDF})$

Crystallographic information file of $\left(\mathrm{FC}_{2} \mathrm{H}_{4} \mathrm{NH}_{3}\right)_{2} \mathrm{PbCl}_{4}$ and $\left(\mathrm{FC}_{2} \mathrm{H}_{4} \mathrm{NH}_{3}\right) \mathrm{PbBr}_{3} \cdot \mathrm{DMF}(\mathrm{CIF})$

\section{AUTHOR INFORMATION}

\section{Corresponding Author}

*E mail: B.Lotsch@fkf.mpg.de.

\section{Author Contributions}

All authors have given approval to the final version of the manuscript.

\section{Notes}

The authors declare no competing financial interest.

\section{ACKNOWLEDGMENTS}

Financial support by the Max Planck Society, "Deutsche Telekom Stiftung" (scholarship for C.L.), the cluster of excellence "Nanosystems Initiative Munich" (NIM), and the Center for NanoScience (CeNS) is gratefully acknowledged. The authors thank the group of Prof. Thomas Klapötke for the possibility to use their DSC calorimeter and Marc Bölter, M.Sc., 
for assistance. We also thank Christine Stefani (Dinnebier group, MPI FKF) for carrying out the temperature dependent PXRD measurements and Ewald Schmitt (Maier department, MPI FKF) for performing further DSC measurements. L.M.S. gratefully acknowledges financial support by the Minerva fast track program.

\section{REFERENCES}

(1) Mitzi, D. B. Synthesis, Structure, and Properties of Organic Inorganic Perovskites and Related Materials. In Progress in Inorganic Chemistry; Karlin, K. D., Ed.; John Wiley \& Sons, Inc.: New York, NY, 1999; pp 1-121.

(2) Baikie, T.; Fang, Y.; Kadro, J. M.; Schreyer, M.; Wei, F.; Mhaisalkar, S. G.; Graetzel, M.; White, T. J. Synthesis and crystal chemistry of the hybrid perovskite $\left(\mathrm{CH}_{3} \mathrm{NH}_{3}\right) \mathrm{PbI}_{3}$ for solid state sensitised solar cell applications. J. Mater. Chem. A 2013, 1, 5628-5641.

(3) Stranks, S. D.; Eperon, G. E.; Grancini, G.; Menelaou, C.; Alcocer, M. J. P.; Leijtens, T.; Herz, L. M.; Petrozza, A.; Snaith, H. J. Electron Hole Diffusion Lengths Exceeding 1 Micrometer in an Organometal Trihalide Perovskite Absorber. Science 2013, 342, 341-344.

(4) Shi, S.; Li, Y.; Li, X.; Wang, H. Advancements in all solid state hybrid solar cells based on organometal halide perovskites. Mater. Horiz. 2015, 2, 378-405.

(5) Service, R. F. Turning Up the Light. Science 2013, 342, 794-797.

(6) Mitzi, D. B.; Feild, C. A.; Harrison, W. T. A.; Guloy, A. M. Conducting tin halides with a layered organic based perovskite structure. Nature 1994, 369, 467-469.

(7) Smith, I. C.; Hoke, E. T.; Solis Ibarra, D.; McGehee, M. D.; Karunadasa, H. I. A Layered Hybrid Perovskite Solar Cell Absorber with Enhanced Moisture Stability. Angew. Chem. 2014, 126, 11414-11417. Smith, I. C.; Hoke, E. T.; Solis Ibarra, D.; McGehee, M. D.; Karunadasa, H. I. A Layered Hybrid Perovskite Solar Cell Absorber with Enhanced Moisture Stability. Angew. Chem., Int. Ed. 2014, 53, 11232-11235.

(8) Quan, L. N.; Yuan, M.; Comin, R.; Voznyy, O.; Beauregard, E. M.; Hoogland, S.; Buin, A.; Kirmani, A. R.; Zhao, K.; Amassian, A.; Kim, D. H.; Sargent, E. H. Ligand Stabilized Reduced Dimensionality Perov skites. J. Am. Chem. Soc. 2016, 138, 2649-2655.

(9) Cao, D. H.; Stoumpos, C. C.; Farha, O. K.; Hupp, J. T.; Kanatzidis, M. G. 2D Homologous Perovskites as Light Absorbing Materials for Solar Cell Applications. J. Am. Chem. Soc. 2015, 137, 7843-7850.

(10) Goldschmidt, V. M. Die Gesetze der Krystallochemie. Naturwissenschaften 1926, 14, 477-485.

(11) Kieslich, G.; Sun, S.; Cheetham, A. K. Solid state principles applied to organic inorganic perovskites: new tricks for an old dog. Chem. Sci. 2014, 5, 4712-4715.

(12) Im, J. H.; Chung, J.; Kim, S. J.; Park, N. G. Synthesis, structure, and photovoltaic property of a nanocrystalline $2 \mathrm{H}$ perovskite type novel sensitizer $\left(\mathrm{CH}_{3} \mathrm{CH}_{2} \mathrm{NH}_{3}\right) \mathrm{PbI}_{3}$. Nanoscale Res. Lett. 2012, 7, 353.

(13) Dalvi, V. H.; Rossky, P. J. Molecular origins of fluorocarbon hydrophobicity. Proc. Natl. Acad. Sci. U. S. A. 2010, 107, 13603-13607.

(14) Frost, J. M.; Butler, K. T.; Brivio, F.; Hendon, C. H.; van Schilfgaarde, M.; Walsh, A. Atomistic Origins of High Performance in Hybrid Halide Perovskite Solar Cells. Nano Lett. 2014, 14, 2584-2590.

(15) Altomare, A.; Burla, M. C.; Camalli, M.; Cascarano, G. L.; Giacovazzo, C.; Guagliardi, A.; Moliterni, A. G. G.; Polidori, G.; Spagna, R. SIR97: a new tool for crystal structure determination and refinement. J. Appl. Crystallogr. 1999, 32, 115-119.

(16) Sheldrick, G. M. A short history of SHELX. Acta Crystallogr., Sect. A: Found. Crystallogr. 2008, 64, 112-122.

(17) Sheldrick, G. M. SHELXL 97: Program for the Refinement of Crystal Structures; Universität Göttingen, 1997.

(18) Topas Academic, version 4.1; Coelho Software: Brisbane, Australia, 2007.

(19) Blaha, P.; Schwarz, K.; Madsen, G.; Kvasnicka, D.; Luitz, J. WIEN2k, An Augmented Plane Wave+ Local Orbitals Program for Calculating Crystal Properties; Technische Universität: Wien, Austria, 2001.
(20) Singh, D. J.; Nordström, L. Planewaves, Pseudopotentials, and the LAPW Method; Springer: New York, NY, 2006.

(21) Madsen, G. K. H.; Blaha, P.; Schwarz, K.; Sjöstedt, E.; Nordström, L. Efficient linearization of the augmented plane wave method. Phys. Rev. B: Condens. Matter Mater. Phys. 2001, 64, 195134.

(22) Sjöstedt, E.; Nordström, L.; Singh, D. J. An alternative way of linearizing the augmented plane wave method. Solid State Commun. 2000, 114, 15-20.

(23) Perdew, J. P.; Burke, K.; Ernzerhof, M. Generalized Gradient Approximation Made Simple. Phys. Rev. Lett. 1996, 77, 3865-3868.

(24) Steiner, T. Die Wasserstoffbrücke im Festkörper. Angew. Chem. 2002, 114, 50-80. Steiner, T. The Hydrogen Bond in the Solid State. Angew. Chem., Int. Ed. 2002, 41, 48-76.

(25) Meresse, A.; Daoud, A. Bis(n propylammonium) tetrachlor oplumbate. Acta Crystallogr., Sect. C: Cryst. Struct. Commun. 1989, 45, 194-196.

(26) Mitzi, D. B. A Layered Solution Crystal Growth Technique and the Crystal Structure of $\left(\mathrm{C}_{6} \mathrm{H}_{5} \mathrm{C}_{2} \mathrm{H}_{4} \mathrm{NH}_{3}\right)_{2} \mathrm{PbCl}_{4}$. J. Solid State Chem. 1999, 145, 694-704.

(27) Mousdis, G. A.; Papavassiliou, G. C.; Raptopoulou, C. P.; Terzis, A. Preparation and characterization of $\left[\mathrm{H}_{3} \mathrm{~N}\left(\mathrm{CH}_{2}\right)_{6} \mathrm{NH}_{3}\right] \mathrm{PbI}_{4}$ and similar compounds with a layered perovskite structure. J. Mater. Chem. 2000, 10, 515-518.

(28) Dohner, E. R.; Jaffe, A.; Bradshaw, L. R.; Karunadasa, H. I. Intrinsic White Light Emission from Layered Hybrid Perovskites. J. Am. Chem. Soc. 2014, 136, 13154-13157.

(29) Muljarov, E. A.; Tikhodeev, S. G.; Gippius, N. A.; Ishihara, T. Excitons in self organized semiconductor/insulator superlattices: $\mathrm{PbI}$ based perovskite compounds. Phys. Rev. B: Condens. Matter Mater. Phys. 1995, 51, 14370-14378.

(30) Kawano, N.; Koshimizu, M.; Sun, Y.; Yahaba, N.; Fujimoto, Y.; Yanagida, T.; Asai, K. Effects of Organic Moieties on Luminescence Properties of Organic-Inorganic Layered Perovskite Type Com pounds. J. Phys. Chem. C 2014, 118, 9101-9106.

(31) Braun, M.; Tuffentsammer, W.; Wachtel, H.; Wolf, H. C. Tailoring of energy levels in lead chloride based layered perovskites and energy transfer between the organic and inorganic planes. Chem. Phys. Lett. 1999, 303, 157-164.

(32) Papavassiliou, G. C.; Vidali, M. S.; Pagona, G.; Mousdis, G. A.; Karousis, N.; Koutselas, I. Effects of organic moieties on the photoluminescence spectra of perovskite type tin bromide based compounds. J. Phys. Chem. Solids 2015, 79, 1-6.

(33) Kitazawa, N.; Watanabe, Y. Optical properties of natural quantum well compounds $\left(\mathrm{C}_{6} \mathrm{H}_{5} \mathrm{C}_{\mathrm{n}} \mathrm{H}_{2 \mathrm{n}} \mathrm{NH}_{3}\right)_{2} \mathrm{PbBr}_{4}(\mathrm{n}=1-4) . J$. Phys. Chem. Solids 2010, 71, 797-802.

(34) Stranks, S. D.; Burlakov, V. M.; Leijtens, T.; Ball, J. M.; Goriely, A.; Snaith, H. J. Recombination Kinetics in Organic Inorganic Perovskites: Excitons, Free Charge, and Subgap States. Phys. Rev. Appl. 2014, 2, 034007.

(35) Hu, T.; Smith, M. D.; Dohner, E. R.; Sher, M. J.; Wu, X.; Trinh, M. T.; Fisher, A.; Corbett, J.; Zhu, X. Y.; Karunadasa, H. I.; Lindenberg, A. M. Mechanism for Broadband White Light Emission from Two Dimensional (110) Hybrid Perovskites. J. Phys. Chem. Lett. 2016, 7, $2258-2263$ 